\title{
Algumas considerações sobre os primeiros livros de lógica moderna editados no Brasil
}

\section{Some considerations about the first modern logic books published in Brazil}

\author{
DOI: $10.46814 /$ lajdv2n6-029
}

Recebimento dos originais: 01/09/2020

Aceitação para publicação: 30/10/2020

\section{Carlos Roberto de Moraes}

Formação Acadêmica mais alta: Doutor em Educação Matemática pela UNESP Rio Claro Instituição de atuação atual: Centro Universitário da Fundação Hermínio Ometto - FHO - Uniararas Endereço completo: pessoal: Avenida 40, 1912 Rio Claro - Sp. CEP 13504268

E-mail: carlosmoraes@fho.edu.br

\section{RESUMO}

Neste trabalho abordaremos três obras que foram relevantes na história da lógica no Brasil: As Ideas Fundamentaes da Matemática, de Manuel Amoroso Costa; Elementos de Lógica Matemática, de Vicente Ferreira da Silva e O Sentido da Nova Lógica, de Willian Van Orman Quine, este último, mesmo não sendo brasileiro, escreveu esse livro quando esteve no Brasil a convite da Escola de Sociologia e Política da USP. A idéia é verificar a relevância, principalmente desta última obra comparando-a a uma obra importante publicada na mesma época de autoria de Alfred Tarsky, intitulada "Introduction to Logic and to the methodology of deductive sciences", publicada em 1941. Essas três obras fazem parte do inicio das publicações nesta área do conhecimento e acreditamos que influenciaram o desenvolvimento dessa importante linha de pesquisa no Brasil.

Palavras-chave: História da Matemática no Brasil, História da Lógica no Brasil.

\begin{abstract}
In this study, we will discuss three books that were relevant in the history of logic in Brazil: As Ideas Fundamentaes da Matemática, by Manuel Amoroso Costa; Elementos de Lógica Matemática, by Vicente Ferreira da Silva e O Sentido da Nova Lógica, by Willian Van Orman Quine, who, although was not Brazilian, wrote this book when he came to Brazil invited by the School of Sociology and Politics of the University of Sao Paulo. The idea is to verify the relevance, mainly of the latter book comparing it to an important work published at the same period, authored by Alfred Tarsky in 1941, entitled "Introduction to Logic and to the methodology of deductive sciences". These three works are part of the beginning of publications in this area of knowledge and believe that influenced the development of this important line of research in Brazil.
\end{abstract}

Keywords: History of Mathematics in Brazil, History of Logic in Brazil.

Este artigo é parte de uma pesquisa de caráter bibliográfico e o procedimento utilizado consistiu num primeiro momento de uma busca de informações em acervos de bibliotecas reais e virtuais. O primeiro passo foi realizar uma consulta a verbete Matemática da Enciclopédia Mirador (1975) que forneceu o título de duas obras relacionadas à lógica. As obras são Elementos de Lógica Matemática de Vicente Ferreira da Silva, publicada em 1940 e O Sentido da Nova Lógica de Willian 
Van Orman Quine, publicada em 1944, este último, mesmo não sendo brasileiro, escreve seu livro originalmente em português, quando de sua estada no Brasil. A luz das informações obtidas nesta busca bibliográfica foi possível obter também informações sobre a obra As Idéas Fundamentaes da Mathematica de Manuel Amoroso Costa, publicada em 1929. Neste ponto encontramos a primeira dificuldade: onde conseguir essas obras para consulta? O livro de W. Quine foi encontrado na Biblioteca da Universidade de São Paulo - USP. O livro de Vicente Ferreira da Silva foi obtido por empréstimo junto à biblioteca da Universidade de São Paulo - USP em 2004 e ao solicitá-lo novamente no final de 2005, o empréstimo já não foi possível tendo em vista o fato do exemplar que se encontrava no Instituto de Matemática ter sido extraviado e por esse motivo o único exemplar restante, na Faculdade de Direito, não pode ser mais disponibilizado através do empréstimo entre bibliotecas. O livro de Manuel Amoroso Costa pode ser encontrado na Universidade de Campinas UNICAMP.

Em virtude dessa dificuldade para obter tais obras julgamos relevante apresentar o que é tratado em tais obras.

O livro As Idéias Fundamentaes da Mathematica de Manuel Amoroso Costa, publicado postumamente, dedica um capítulo à Lógica Matemática. Na seqüência faremos algumas considerações biográficas sobre o autor e sobre o capítulo relacionado à lógica matemática.

\section{MANUEL AMOROSO COSTA ( 1885 - 1928)}

Manuel Amoroso Costa, filho de Cypriano de Oliveira Costa e Francisca Julieta Amoroso de Oliveira Costa, nasceu em 13 de janeiro de 1885, no Rio de Janeiro. Cursou as humanidades no Collegio Kopke e ingressou na Escola Politécnica do Rio de Janeiro em 1900, aos 15 anos de idade, concluiu seus estudos em 1906, tendo obtido o bacharelado em ciências físicas e matemáticas e engenharia civil. Foi aluno de Otto Alencar Silva, de quem recebeu forte influência.

Entre 1911 e 1914 trabalhou no escritório técnico da Repartição Federal de Fiscalização das Estradas de Ferro. No ano de 1912 foi nomeado preparador da cadeira de Aplicações Industriaes $e$ Electrotechnica da Escola Politécnica. Em fevereiro de 1913 foi habilitado à livre docência da secção de Topografia e Astronomia com o trabalho "Sobre a Formação das Estrellas duplas". Em novembro tornou-se professor extraordinário efetivo e em 21 de maio de 1924 tornou-se catedrático de Trigonometria Espherica, Astronomia theorica e pratica, e Geodesia.

Realizou viagens de estudo à Europa em 1920 e 1924. Em março de 1928, a convite do Instituto Franco-Brasileiro de Alta Cultura, ministrou um curso Les Géométries non archimédiennes na Universidade de Paris e apresentou no Collège de France um trabalho intitulado L'univers infini Quelques aspects du problème cosmologique. Vem a óbito a três de dezembro de 1928 num acidente 
aéreo na Baia da Guanabara, no Rio de Janeiro, em um vôo programado para homenagear Santos Dumont, que regressava ao Brasil.

Em 1929, no Rio de Janeiro, Manuel Amoroso da Costa teve postumamente publicado seu livro "As Idéas Fundamentaes da Mathematica", que expõe em linhas gerais a concepção da época sobre matemática pura e dedica um capítulo à lógica simbólica e à matemática, e que talvez seja a primeira obra a apresentar a "moderna" lógica matemática no Brasil. Como diz Amoroso Costa na introdução:

\begin{abstract}
Analisando a dedução matemática, geômetras e filósofos reconheceram de há muito tempo que ela não cabe na lógica dedutiva clássica, a silogística de Aristóteles, desenvolvida pela Escolástica e pouco modificada desde então. A dedução matemática não se faz apenas por silogismos, porém sobretudo de acordo com outros tipos de raciocínio que os trabalhos recentes isolaram, e que merecem, não menos que o silogismo, ser considerados como leis extrínsecas do pensamento. Daí a ampliação moderna da lógica formal, servida por um algoritmo simbólico análogo ao da matemática, e possuindo todos os caracteres de um rigoroso algebrismo."(AMOROSO COSTA, 1929, p. 12)
\end{abstract}

O capítulo V intitulado A Lógica Simbólica e a Matemática apresenta uma breve resenha histórica onde o autor credita a origem da lógica simbólica aos trabalhos de Leibniz.

Os trabalhos de Leibniz e seus discípulos ficaram por um longo tempo em completo esquecimento. O século XIX marca o renascimento desses estudos com os logicistas ingleses. O autor destaca George Boole com sua obra Mathematical Analysis of Logic, publicado em 1847. Uma das características do trabalho de Boole é a introdução de dois símbolos, 1 e 0 , representando o universo lógico e o nada lógico, respectivamente. Desta forma Boole consegue obter um conjunto de regras de calculo lógico, graças às quais se efetuam mecanicamente longas e complexas cadeias dedutivas. De acordo com o autor Boole pode ser considerado o criador da lógica simbólica, no que se refere ao cálculo das classes.

São destacados os autores ingleses Augustus de Morgan, John Venn e William Stanley Jevons que contribuíram para o desenvolvimento e o aperfeiçoamento dos trabalhos de Boole. De acordo com o autor,

a álgebra da lógica completou-se, com o cálculo das relações, entrevisto por Leibniz, esboçado por C. S. Peirce e E. Schröder, e que se constituiu com os trabalhos de G. Frege, G. Peano, A. N. Whitehead e B. Russell (AMOROSO COSTA, 1929, p. 57).

O autor apresenta o trabalho de Peano e seus colaboradores enfatizando a utilização da lógica simbólica como instrumento da demonstração matemática. 
O final do esboço histórico é marcado pela escola inglesa de Russell e Whitehead, onde são levadas às últimas consequiências a tese de Frege: a matemática pura contém exclusivamente os conceitos fundamentais da Lógica.

São citados os livros Universal Algebra de Whitehead de 1898, Principles of Mathematics, de Russell, de 1903 e o Principia Mathematica, de Whitehead e Russell, publicado entre 1910 e 1913. Amoroso Costa fica impressionado com o desenvolvimento considerável do simbolismo ideográfico e com a pouca utilização da linguagem vulgar no texto do Principia e, assumindo seu papel de divulgador das novas idéias procura dar uma visão geral desta obra.

Amoroso Costa inicia com o cálculo das proposições, onde Russell e Whitehead adotam seis idéias primitivas e algumas definições. As idéias primitivas são: proposição elementar, função proposicional elementar, asserção de uma proposição (representada pelo símbolo $\vdash$ ), asserção de uma função proposicional, negação de uma proposição (representada pelo símbolo ) e a disjunção ou soma lógica de duas proposições (representada pelo símbolo $\vee$ ). Além dessas idéias primitivas temos algumas definições:

1) Implicação entre duas proposições, com a notação $\mathrm{p} \supset \mathrm{q} .=. \sim \mathrm{p} \vee \mathrm{q}$

2) Produto lógico de duas proposições, com a notação p.q. $=. \sim(\sim \mathrm{p} \vee \sim \mathrm{q})$

3)Equivalência material de duas proposições, com a notação $\mathrm{p} \equiv \mathrm{q} .=. \mathrm{p} \supset \mathrm{q} \cdot \mathrm{q} \supset \mathrm{p}$

Após as idéias primitivas e as definições derivadas são apresentados dez postulados que, segundo Whitehead e Russell, serão as leis da lógica dedutiva e também são colocados os conceitos de classes e relações. É interessante observar que, a notação utilizada para exprimir que x é membro de uma classe $\alpha$ é a utilizada por Peano $\mathrm{x} \in \alpha$.

Amoroso Costa apresenta também propriedades das relações: simétrica, não-simétrica, assimétrica, transitiva, não-transitiva e intransitiva. Whitehead e Russell procuraram demonstrar que toda a matemática pura trabalha exclusivamente com conceitos que podem ser definidos em termos dos conceitos lógicos primitivos, e que todas as suas proposições podem ser deduzidas a partir dos princípios lógicos apresentados acima. Hoje sabemos que isso não é verdadeiro, o trabalho de Gödel mostrou a impossibilidade de tal feito proposto pelos logicistas ingleses, mas tal trabalho aparece depois da obra de Amoroso Costa ter sido publicada.

É importante ressaltar o cuidado que Amoroso Costa teve ao apresentar a proposta de Whitehead e Russell

Seria temerário affirmar que ella executou integralmente e impecavelmente o seu programma, ou mesmo que o programma seja exeqüível. A lógica simbolyca actual nos parecerá algum dia tão estreita como nós já hoje consideramos a lógica clássica. E quando mesmo toda a nossa mathematica actual se possa exprimir em termos de um systema de 
noções primitivas, nada prova que o seu desenvolvimento ulterior dispense a adjuncção de novas noções primitivas. (AMOROSO COSTA, 1929, p. 71)

Amoroso Costa ressalta a importância da lógica formal para o desenvolvimento do pensamento matemático ao afirmar que o simbolismo utilizado pela lógica formal "permitte a analyse rigorosa das articulações do raciocínio, evitando as causas de erro inherentes ao emprego da linguagem comum" (AMOROSO COSTA, 1929, p. 52).

O primeiro livro texto de lógica moderna aparece em São Paulo, em 1940, quando Vicente Ferreira da Silva (1916 - 1963) publica "Elementos de Lógica Matemática”, que apresenta alguns tópicos importantes da chamada lógica matemática, embora não apresente algo essencialmente original. Trata-se de uma obra de caráter didático e elementar, o que segundo (COSTA, 1964, p.499) "torna quase impossível de se perceber as idéias originais que sobre o assunto ele porventura pudesse ter".

Apresentaremos uma breve biografia sobre o autor e, em seguida, abordaremos o que é tratado nesta obra.

\section{VICENTE FERREIRA DA SILVA (1916 - 1963)}

Vicente Ferreira da Silva nasceu em São Paulo a 10 de janeiro de 1916. Estudou no Colégio de São Bento e mais tarde se formou em Direito, mas nunca exerceu a profissão de advogado. Trabalhou com o filósofo americano Willard van Orman Quine, quando o conhecido professor de Harvard esteve em São Paulo a convite da Escola de Sociologia e Política da USP. Ministrou diversos cursos livres de filosofia e de acordo com (CARVALHO, 2005) "fundou, em 1945, em São Paulo, o Colégio Livre de Estudos Superiores, com base no Colegio Libre de Estúdios Superiores que conheceu em Buenos Aires". Ainda em 1945 se tornou colaborador efetivo do Suplemento Letras e Artes do Jornal A Manhã. Em 1949, organizou o Seminário de Filosofia do Museu de Arte Moderna. Neste mesmo ano, ao lado de Miguel Reale, foi o co-fundador do Instituto Brasileiro de Filosofia. Em 1950, escreve Dialética das Consciências, ensaio que marca sua posição existencialista. O texto fora preparado para um concurso de filosofia na USP, concurso que Vicente Ferreira da Silva foi impedido de fazer. No ano de 1954 fundou, juntamente com a esposa, a poetisa Dora Ferreira da Silva, a Sociedade Cultural Nova Crítica, que publicou a revista Diálogo. Ainda em 1954, atuou como um dos organizadores do I Congresso Internacional de Filosofia ao lado de Miguel Reale. Em 1963 vem a óbito num trágico acidente automobilístico.

$\mathrm{Na}$ introdução do seu livro o autor afirma que 
produto independente e exterior á velha lógica aristotélica, mas sim representa uma nova sistematização e refundição dessa mesma lógica. Todos os capítulos segundo os quais a lógica clássica se achava dividida, sofreram críticas, remodelações e ampliações. Tanto na teoria dos termos, como na teoria das proposições e na teoria da argumentação, surgiram novos horizontes, desconhecidos nas cogitações dos lógicos do passado. Lógica matemática, é o nome que designa esta nova lógica. Frizemos o fato de que a palavra matemática, não implica neste caso, a intromissão da matemática comumente compreendida, no método desta disciplina, mas simplesmente sublinha a precisão e clareza com que são estabelecidas as verdades, nesta nova fase do desenvolvimento da lógica. (SILVA, 1940, p.7)

O autor afirma que a lógica matemática tem como característica a independência que esta área do conhecimento tem em relação à filosofia, "a lógica desenvolveu-se ultimamente como uma ciência autônoma, com objeto e métodos próprios, aspirando a verdades próprias" (SILVA, 1940, p. 9).

O capitulo 1 intitulado A Lógica, como base da Filosofia apresenta a lógica como método da filosofia. É nítida a influência de Bertrand Russell e de outros membros do Círculo de Viena quando o autor sustenta que a lógica matemática deve constituir a base da pesquisa filosófica.

Ainda no capítulo 1 o autor defende a lógica como uma ciência em evolução, aberta e viva e apresenta uma descrição do alcance das investigações lógicas a alguns problemas concretos, procurando ressaltar sua utilidade em filosofia. Neste ponto ficam evidenciadas algumas idéias filosóficas do Círculo de Viena, e para os filósofos dessa escola, a filosofia se resume a uma clarificação dos nossos pensamentos e conceitos. "Esses pensadores procuram examinar com atenção as formulações das questões filosóficas e inquirir com um rigor lógico, o que estas questões pretendem significar" (SILVA, 1940, p. 25).

No capítulo II, intitulado A Nova Doutrina do Termo - Estudo Sumario das Descrições, o autor procura, em primeiro lugar, destacar a importância do estudo da lógica realçando a necessidade de uma linguagem precisa. Como escreve o autor

A linguagem é um aparelhamento cheio de peias e quem não tiver a ciência de sua estrutura e fim, cairá fatalmente em suas armadilhas.

Eis então, o motivo da importância do estudo da lógica. Nesta, sob um ponto de vista especial, o raciocínio estuda o raciocínio, desvenda-lhe os mistérios, analisa-lhe as partes; a definição é definida, ajuíza-se sobre os juízos" (SILVA, 1940, p. 26).

$\mathrm{Na}$ seqüência, enfatiza que a lógica investiga o raciocínio de um ponto distinto da psicologia e passa a tratar a teoria dos termos. Neste ponto o autor afirma que o tratamento que os lógicos clássicos davam à teoria dos termos apresentava-se completamente defeituoso. $\mathrm{O}$ defeito reside no fato de serem apresentadas considerações de ordem psicológica, epistemológica e, portanto, extra-lógicas como partes constituintes da teoria dos termos. Tal fato aparece em todos os compêndios de lógica publicados em português. 
A seguir é tratado o que vem a ser uma asserção e em seguida é feito um exame dos elementos integrantes das asserções - os termos. São também examinados certos elementos que exercem, da mesma forma que os termos, a função substantiva dentro do ambiente proposicional, mas que não podem ser isolados do contexto da asserção: as descrições.

O capítulo III, intitulado A Teoria das Proposições Atômicas. A forma S é P e a forma xRy, começa definindo uma proposição como sendo um agregado de palavras ou símbolos pelos quais são veiculadas a verdade ou a falsidade. São chamadas de proposições atômicas os enunciados que versam sobre fatos imediatos de experiência, por exemplo, "isto é preto".

$\mathrm{Na}$ seqüência são estudadas algumas propriedades importantes de uma relação. Uma relação pode ser simétrica, assimétrica, transitiva e intransitiva.

O capítulo IV, intitulado As Proposições Moleculares e as Leis da lógica, apresenta estudos sobre o produto, a soma e a negação lógica, que constituem as operações lógicas fundamentais, utilizando os esquemas de Wittgenstein . A partir delas podemos definir as outras relações (a implicação e a equivalência) em função dessas operações. A asserção "este livro é preto ou branco" permite observar dois juízos: "Este livro é branco" (p) e "Este livro é preto" (q), unidos pela disjunção $o u$, o que pode ser escrito como "p ou q". O autor ressalta que alguns lógicos do século XIX, entre os quais Boole e Schröder, através da analogia entre as combinações de proposições e as combinações aritméticas dos números, organizaram um algoritmo e uma álgebra própria das proposições, que ficou conhecida como cálculo proposicional.

O capítulo V, intitulado $O$ Cálculo Proposicional, apresenta algumas leis célebres da lógica clássica de maneira dedutiva, propiciando assim um exemplo de funcionamento da lógica matemática. Temos também a demonstração de alguns princípios lógicos, como, por exemplo, o princípio de redução ao absurdo e o princípio do terceiro excluído (ou A é x ou é y e não há terceira possibilidade). Além disso ensina, através de cálculos algébricos, a transformar certas fórmulas em outras, obtendo diversos teoremas lógicos.

O capítulo VI, intitulado A noção de Função Proposicional e sua aplicação, apresenta o conceito de função proposicional como sendo o símbolo que expressa uma correspondência entre um dado grupo de objetos e um certo grupo de proposições. São apresentados também os conceitos de operador universal e operador existencial. Com as noções adquiridas nesse capítulo é feita uma análise das asserções $\mathrm{A}, \mathrm{E}, \mathrm{I}, \mathrm{O}$ da lógica clássica, respectivamente a afirmativa e a negativa universal e a afirmativa e a negativa particular e, entre as conclusões, tem-se que certas formas de inferências imediatas, estabelecidas na lógica clássica são errôneas. Por exemplo, da proposição “Todos os A são B”, não podemos deduzir formalmente a proposição "Alguns B são A". 
O capítulo VII, As Classes, define como classe ou conjunto a um sistema de objetos onde todos possuem uma mesma propriedade. Apresenta ainda o conceito de classe de classes, isto é, um conjunto cujos elementos são conjuntos. A seguir são apresentados dois princípios distribuídos entre as operações soma e produto lógico: a lei distributiva do produto em relação a soma e a lei distributiva da soma em relação ao produto lógico. Tais princípios são ilustrados pelo sistema de circunferências de Euler.

O capítulo VIII, As Leis da Dedução, é marcado por algumas críticas formuladas pela lógica moderna contra a concepção aristotélica da teoria da argumentação e expõe alguns exemplos de argumentação assilogísticas comumente empregados, como por exemplo, a lei da "redução ao absurdo”. O autor ainda observa que na lógica moderna, tendo sido ampliada a noção de proposição, foram reconhecidas novas formas de inferência, que não encontravam abrigo na lógica aristotélica.

No último capítulo, As Determinações Verdade e Falsidade, o autor faz uma crítica ao fato de os lógicos clássicos admitirem que qualquer proposição com forma gramatical correta seja necessariamente verdadeira ou falsa. Do ponto de vista da lógica clássica, tanto a proposição (1) “O sol não ilumina", como a proposição (2) "O branco é um número", eram consideradas "falsas". A lógica moderna, entretanto, admite que a proposição (1) é falsa ao passo que a proposição (2), deve ser chamada "sem sentido". O autor aborda a teoria dos tipos, que estabelece as regras segundo as quais uma sentença deve ser construída, para evitar o sem-sentido. O capítulo é finalizado com um quadro onde as proposições podem ser classificadas em "sem sentido" ou "com sentido" e, neste último grupo, podemos ter as verdadeiras, as falsas, as válidas e as inválidas.

\section{WILLARD VAN ORMAN QUINE (1908 - 2000)}

Willard Van Orman Quine nasceu a 25 de junho de 1908 na cidade de Akron, no estado de Ohio (EUA), filho Cloyd Robert Quine e Harriet Van Orman Quine. Graduou-se no Oberlin College em 1930. Em 1932 obteve seu PhD sob a orientação de Alfred North Whitehead. Inicialmente tendo a Lógica como seu principal campo de interesse e objetivando se aperfeiçoar em tal campo visitou Viena, Praga e estudou lógica com Rudolf Carnap. Em 1936 tornou-se professor em Harvard. Quine foi um dos mais influentes filósofos e lógicos norte-americanos do século XX, considerado o maior filósofo analítico da segunda metade deste século. Morreu a 25 de dezembro de 2000, em Boston (EUA).

Quine visitou o Brasil em 1942, a convite da Escola de Sociologia e Política anexa a USP e convidou Vicente Ferreira da Silva para ser seu assistente, durante o período em que ministrou o curso de lógica matemática. Deste curso nasceu, em 1944, o livro O Sentido da Nova Lógica, hoje uma raridade bibliográfica. 
O livro é dividido em quatro partes: I - Teoria da composição, II - Teoria da quantificação, III - Identidade e Existência e IV - Classe, Relação e Número.

No prefácio o autor afirma que

A sistematização lógica específica usada neste trabalho resulta dum esforço para conciliar três ideais: rigor nos detalhes teóricos, conveniência nas aplicações práticas, e simplicidade na apresentação. Este último ideal foi o objetivo principal” (QUINE, 1944, p. 9)

Dentro desta proposta o autor constrói um livro onde a introdução apresenta algumas considerações históricas ressaltando que a evolução sofrida pela lógica nos últimos noventa anos permite considerá-la uma ciência nova, ressalta as contribuições do inglês George Boole, dos alemães Frege e Schröder, do norte-americano Charles Peirce, do italiano Peano, e segundo Quine a lógica atinge um estado de amadurecimento apreciável com a publicação da obra Principia Mathematica dos ingleses Whitehead e Russell. Ainda dentro dessas considerações históricas escreve sobre a lógica aristotélica, ressaltando o fato de a mesma ter sobrevivido até a Idade Média sem sofrer mudança ou progresso importante. Lembra que Kant, na segunda metade do século XVIII, podia "falar da lógica formal como duma ciência que já se aperfeiçoara, já se completara, dois mil anos atrás" (QUINE, 1944, p.12).

No entanto o progresso da matemática chegou a tal ponto que o papel dos métodos dedutivos teve que ser revisto e um dos motivos para esta revisão foi o estudo do alemão Cantor, no final do século XIX, sobre as classes infinitas. Além disso, no início do século XX,

com a descoberta feita pelo lógico inglês Bertrand Russell, que os princípios do raciocínio aceitos e usados tacitamente em matemática, e talvez fora dela, são capazes de envolver-nos em contradições. Esta descoberta precipitou uma crise. Os princípios da lógica dedutiva tiveram que ser explícita e cuidadosamente formulados e mesmo revistos, para que a matemática em geral fosse bem fundada. (QUINE, 1944, p.14).

Segundo Quine, a descoberta dos paradoxos e outras noções que necessitavam esclarecimento por definição baseada em noções claras como, por exemplo, os infinitésimos e os números imaginários, contribuíram para o que ele chama de o ressurgimento da lógica.

$\mathrm{Na}$ parte final da introdução escreve sobre o trabalho do lógico austríaco Kurt Gödel que demonstrou, em 1931, não ser possível existir uma sistematização coerente dentro da qual todo enunciado verdadeiro da matemática seja demonstrável. "Dada qualquer sistematização da lógica, haverá verdades lógicas e mesmo aritméticas, demonstravelmente indemonstráveis" (QUINE, 1944, p. 20).

O autor conclui a introdução afirmando que 
Ao cientista ansioso por técnicas não quantitativas, a lógica matemática oferece socorro de duas maneiras: provê técnicas explícitas para a manipulação dos mais simples ingredientes da linguagem e provê uma clara e sistemática base, sobre a qual podem ser construídas futuras teorias apropriadas às necessidades cientificas especiais que surgem de vez em quando. (QUINE, 1944, p. 22)

$\mathrm{Na}$ primeira parte do livro, a Teoria da Composição, o autor afirma ser conveniente considerar a lógica, como contendo duas partes: a teoria da dedução e a teoria das classes. A teoria da dedução se divide por sua vez em duas outras partes: a teoria da composição e a teoria da quantificação.

O objetivo desta primeira parte do livro é fornecer os subsídios necessários como preparação a um estudo técnico da primeira parte da lógica, em que se trata da composição de um enunciado. A primeira questão abordada é o que vem a ser um enunciado. Segundo Quine, enunciados são frases, mas nem toda frase é um enunciado. Os enunciados compreendem só aquelas frases que são verdadeiras e aquelas que são falsas. Tais propriedades dos enunciados, verdade e falsidade, chamam-se valores dos enunciados. As frases "que horas são?", "Feche a porta" não sendo nem verdadeiras nem falsas, não são enunciados. Só frases declarativas são enunciados, no entanto, nem todas as frases declarativas são enunciados. Considere, por exemplo, a frase declarativa "Estou cansado" observe que ela não é por si só nem verdadeira nem falsa, pois pode ser afirmada veridicamente por uma pessoa e falsamente por outra. Segundo o autor

as técnicas formais de análise dependerão da suposição de que um enunciado é uma frase verdadeira ou falsa independentemente do contexto, de quem fala, do lugar e tempo de sua afirmação (QUINE, 1944, p. 27).

A teoria da composição trata dos modos de compor enunciados para formar enunciados compostos utilizando os conceitos de conjunção, que consiste em ligar dois enunciados pela palavra "e" - ou, na notação da lógica matemática representada pelo ponto “_،

Carlos está cansado - Carlos está fora

Na sequência, apresenta o conectivo "ou" e como obter a tradução mecânica do exclusivo "ou” e do inclusivo "ou” em termos de conjunção e negação. Trata também do condicional (se p logo q) e chama a atenção para o fato de haver uma confusão infeliz entre "se - logo" e "implica" pois muitas vezes lê-se "p implica q" em lugar de "se p logo q". Segundo o autor

Implicação não é modo de composição de enunciados; é relação entre enunciados, como por exemplo, o amor e o ódio são relações entre pessoas. O verbo "implica", como os verbos "ama" e "odeia", deve colocar-se entre nomes e não entre enunciados (QUINE, 1944, p.51). 
Ainda na primeira parte de seu livro Quine trata da chamada tradução centrípeta que é uma técnica para tradução de um enunciado complexo. O objetivo dessa tradução em termos de conectivos "e" e "negações" têm o efeito de revelar e resolver equívocos, seja no sentido de alguma das ligações usadas na linguagem natural, seja nos modos de agrupamento.

Segundo Quine, as aplicações práticas das técnicas da teoria da composição se realizam, na sua maior parte, dentro da teoria da "quantificação", que é o foco da segunda parte de seu livro. O autor enfatiza que nas ciências naturais não é freqüente que a pesquisa de implicações lógicas entre enunciados seja feita unicamente sobre estruturas composicionais, sem interferência das estruturas quantificacionais. Como exemplo de uma aplicação prática apresenta um trabalho do engenheiro elétrico Claude Elwood Shannon (1916-2001) que utilizou as técnicas da teoria da composição para resolver certos problemas na simplificação de redes elétricas.

A segunda parte do livro intitulada Teoria da Quantificação faz menção ao trabalho de Frege, que segundo o autor, foi o responsável pelo passo mais importante da lógica moderna: a criação da teoria da quantificação.

\begin{abstract}
A teoria governa o uso dos prefixos "(x)", “(y)", etc. chamados quantificadores. Estes se escrevem antes de expressões que têm a forma de enunciados, mas exibem letras " $x$ ", “ $y$ ", etc. em lugar de nomes de objetos. O resultado, chamado um quantitativo, é verdadeiro se, e somente se, a expressão que segue o prefixo permanece verdadeira não importa qual objeto se imagine designado pela letra "x" (ou “y”, etc.). (QUINE, 1944, p. 77)
\end{abstract}

O prefixo “(x)" pode ser lido como "seja x qual for" ou "todo objeto x é tal que". Desta forma, "(x) x existe" significa "Todo objeto x é tal que x existe". A quantificação corresponde de maneira indireta ao uso natural da palavra "todo". Tal correspondência é indireta, pois "todo objeto" do ponto de vista sintático aparece como substantivo, embora a quantificação não apresente nenhum substantivo correspondente. Segundo Quine a falta dessa correspondência sintática é uma vantagem do procedimento da teoria da quantificação, pois a forma substantiva da expressão "tudo" ou "todo objeto" é uma forma enganadora da linguagem natural. Isto pode ser visto no seguinte exemplo:

(1) Todo objeto é homem ou difere do homem.

(x) (x é homem ou $\mathrm{x}$ difere de homem).

(x) $\sim(\sim \mathrm{x}$ é homem $-\sim \mathrm{x}$ difere de homem).

(2) Todo objeto é homem ou todo objeto difere do homem.

(x) $\mathrm{x}$ é homem ou (x) $\mathrm{x}$ difere de homem.

$\sim(\sim(\mathrm{x}) \mathrm{x}$ é homem - $\sim(\mathrm{x}) \mathrm{x}$ difere do homem). 
O composto (2) é falso, sendo ele a ligação por "ou” de dois enunciados falsos; mas (1) é verdadeiro. Após apresentar mais alguns exemplos Quine afirma que "uma vantagem da notação de quantificadores é indicar explicitamente o que se esconde ou se exprime só não sistematicamente na linguagem natural".

Em seguida denomina as letras "x”, “y”, etc., auxiliares à notação de quantificação, como sendo pronomes lógicos. A justificativa para o termo pronome lógico pode ser evidenciada quando observamos que "(x) x existe" pode ser lida como "Todo objeto é tal que ele existe".

Na sequência afirma que a tradução de enunciados da linguagem diária em sinais lógicos continua válida mesmo quando temos que considerar estruturas quantificacionais, além das estruturas composicionais. Neste caso, a tradução torna-se uma tarefa mais complicada e Quine apresenta um exemplo "de ordem especialmente complicada" para esclarecer o caso geral.

Temos também as definições de verdade e validade quantificacional. O autor apresenta a verdade quantificacional como uma espécie de verdade lógica mais inclusiva do que a verdade composicional.

$\mathrm{Na}$ teoria da composição, a técnica exemplificada pelos quadros de valores fornece uma maneira mecânica de verificar se qualquer enunciado é composicionalmente verdadeiro ou não. No caso da técnica apresentada nesta segunda parte do livro temos que; para estabelecer se um dado enunciado é quantificacionalmente verdadeiro, procurar sua derivação a partir da matriz (A) e por meio das operações (i) -(iv). A derivação, quando descoberta, pode ser autenticada por inspeção mecânica; mas a procura desta derivação não é um processo mecânico. Segundo Quine

O que possuímos é, em breve, unicamente um método mecânico de autenticação de demonstrações da verdade quantificacional, e não um critério mecânico para a própria verdade quantificacional. Sabe-se, com efeito, que um tal critério é impossível. A demonstração deste fato é devida a Church (1936) (QUINE, 1944, p. 106)

Temos, ainda, nesta segunda parte a implicação quantificacional que relaciona enunciados cujo condicional é quantificacionalmente verdadeiro; e a equivalência quantificacional que é definida como implicação quantificacional recíproca, pois cada demonstração de equivalência quantificacional consiste na demonstração de duas implicações.

No final da segunda parte temos um item dedicado ao silogismo, o tipo de raciocínio conhecido desde Aristóteles, exemplificado pelo argumento:

"Nenhum $\beta$ é $\gamma$ e todo $\alpha$ é $\beta$; portanto, nenhum $\alpha$ é $\gamma "$ ".

O autor estabelece essa implicação dentro da teoria da quantificação e apresenta um método conveniente para a demonstração de enunciados que contém nomes, sem precisar introduzir a consideração de nomes dentro da teoria da quantificação. 
O último tópico é chamado "Teoria monádica da quantificação", onde o autor afirma que existe um critério mecânico que permite decidir se as matrizes retratadas por um dado esquema são válidas no caso dos esquemas monádicos, enfatizando que esse critério mecânico não é verdadeiro em geral. A porção monádica da teoria da quantificação embora simples é importante, incluindo, em particular, a lógica silogística; e esse fato faz com que a existência de um critério mecânico de validade tenha interesse.

Finalmente, o autor conclui esta parte do livro ressaltando que o domínio das técnicas da quantificação pode ser útil na "vida prática" e exemplifica que tais técnicas podem ser úteis a empresas de seguros, seja na simplificação de contratos ou na verificação de consistência de um conjunto de cláusulas, entre outras. Segundo Quine este campo de aplicação já está sendo explorado pela Prudential Insurance of América, devido aos esforços de Edmund C. Berkeley (1909-1988).

A terceira parte, intitulada Identidade e Existência, o autor inicia com o conceito de identidade, onde afirma que identidade é uma noção tão simples e fundamental que dificilmente admite explicação em termos mais claros, dizer que x e y são idênticos é dizer que são a mesma coisa. "Todo objeto é idêntico a si mesmo e nada mais". (QUINE, 1944, p. 135)

Embora a identidade seja uma noção elementar, tem sido objeto de confusões persistentes. $\mathrm{O}$ autor exemplifica recorrendo a Heráclito "Não nos podemos banhar duas vezes no mesmo rio". O fato das águas de um rio se renovarem continuamente, segundo Heráclito, fará com que seja outro rio no momento do segundo banho. A dificuldade é de conceber como um objeto que muda permanece idêntico a si mesmo. Segundo Quine

\footnotetext{
Consideremos o rio. É um objeto extenso, tanto no tempo como no espaço. É o total de seus diversos estados instantâneos, assim como de suas diversas secções transversais entre a fonte e a foz. O rio não é o total de certas gotas d'água; cada gota compartilha da extensão espacial do rio só dentro duma porção do comprimento temporal da gota e do rio. Agora o rio, mude como mudar, tanto em relação à sua constituição material quanto em relação a outros fatores, permanece o mesmo rio durante toda sua existência; permanece o mesmo idêntico total dos diversos estados instantâneos. (QUINE, 1944, p.136)
}

Outro tipo de confusão sobre a identidade vê-se numa observação de Wittgenstein: "dizer dum objeto que ele é idêntico a si mesmo é oco, e dizer que é idêntico a outro objeto é errado". De acordo com Quine temos que distinguir não entre dois casos, mas entre três, para isso considera os enunciados: 'Cícero $=$ Cícero', 'Cícero $=$ Catalina' e 'Cícero $=$ Túlio'. O primeiro enunciado é oco e o segundo é falso; mas o terceiro não é oco e nem falso. O terceiro é informativo, pois combina dois nomes diversos e além disso é verdadeiro, visto que os dois nomes são nomes do mesmo objeto. Wittgenstein não distinguindo cuidadosamente entre os objetos e os nomes, considera que toda afirmação verdadeira de identidade deve apresentar o sinal ' $=$ ' entre repetições do mesmo nome, 
Wittgenstein não reconhece que '=' deva somente aparecer entre nomes do mesmo objeto, sendo os nomes, em todo caso, nomes diferentes.

Segundo Quine a confusão entre identidade dos objetos e identidade de seus nomes encontra-se na mente de muitos matemáticos que consideram que uma equação, como por exemplo, ' $5+3=6+2$ ', relaciona dois números que são iguais, em algum sentido, mas ainda não idênticos, sendo as expressões ' $5+3$ ' e ' $6+2$ ' diversas. Esta confusão entre sinal e objeto conduz, às vezes, à idéia de que a identidade é uma relação entre os sinais mesmos e não entre os objetos.

Na seqüência, são apresentados os princípios de identidade, sendo o primeiro o princípio da substutividade da identidade, segundo o qual, dado um enunciado verdadeiro de identidade, um dos dois termos pode ser substituído pelo outro em qualquer verdade, permanecendo o resultado verdadeiro. Os outros princípios apresentados no livro são o princípio da transitividade da identidade, que afirma que, sejam $\mathrm{x}, \mathrm{y}$ e $\mathrm{z}$, se $\mathrm{x}=\mathrm{y}$ e $\mathrm{y}=\mathrm{z}, \log \mathrm{x}=\mathrm{z}$, o princípio da simetria da identidade, que registra ser indiferente à ordem numa identidade e o princípio que todo objeto é idêntico à algum objeto.

O tópico seguinte é intitulado Sentido. Sinonímia. Necessidade. O autor inicia enfatizando que dizer que dois nomes designam o mesmo objeto não é dizer que são sinônimos, ou que tem o mesmo sentido. Como exemplo, o autor recorre à astronomia,

o objeto (o número ou grau de multiplicidade) designado pelo ideograma '9' é o mesmo que o designado pelo nome complexo 'o número dos planetas'. A identidade O número de planetas $=9$

é uma verdade (segundo se crê no momento) da astronomia. (QUINE, 1944, p.149)

Os nomes 'o número de planetas' e '9' não são sinônimos e não tem o mesmo sentido. É interessante observar o cuidado do autor quando afirma "segundo se crê no momento", chamando a atenção para o fato de que tal afirmação venha a ser impugnada pela descoberta de outro planeta.

O autor escreve que o sentido de uma expressão ainda não é claro; embora seja claro que, dada a noção de sentido, poderia ser esclarecida a noção de sinonímia como sendo a relação entre quaisquer expressões que têm o mesmo sentido. A recíproca poderia ser obtida também, dada a relação de sinonímia poderíamos considerar o sentido de uma expressão como sendo a classe de todas as expressões sinônimas a ela. Segundo Quine

A relação de sinonímia exige uma definição ou um critério em termos psicológicos e lingüísticos. Tal definição, ainda nem mesmo esboçada, seria uma contribuição fundamental ao mesmo tempo à filologia e à filosofia. (QUINE, 1944, p.150)

O próximo item desta parte do livro é intitulado Existência, onde o autor inicia escrevendo que a palavra 'nome' tem um sentido gramatical e outro semântico. A palavra 'substantivo' será 
encarregada do sentido gramatical, reservando à palavra 'nome' o sentido semântico: o que é nome de um objeto, o que designa.

O autor aborda a questão de um substantivo ser nome e também a questão de dois nomes designarem o mesmo objeto, afirmando que geralmente não se decide pelo estudo do mero sentido das palavras. Para exemplificar, do ponto de vista puramente lingüístico, as palavras 'Pégaso' ${ }^{1}$ e 'Bucéfalo'2 são semelhantes; é somente um acidente da história natural que 'Bucéfalo' designa enquanto que 'Pégaso’ não. Segundo Quine

A questão se dois nomes designam o mesmo objeto equivale à questão se o enunciado de identidade formado dos dois nomes é verdadeiro; e esta verdade pode ser uma verdade da ciência natural. A questão se um substantivo é nome equivale a questão se o enunciado de existência formado do nome é verdadeiro. (QUINE, 1944, p.159)

O enunciado pode ser uma verdade da ciência natural como, por exemplo,

(1) Há Bucéfalo

O enunciado (1) não afirma que ainda vive Bucéfalo, afirma simplesmente que existe de fato, a suposta porção do mundo espaço-temporal.

O enunciado

(2) há Pégaso

nega que haja, um trecho do mundo espaço-temporal sob o substantivo Pégaso. O enunciado (2) é, uma verdade da ciência natural. Talvez haja uma idéia de Pégaso e igualmente uma idéia de Bucéfalo, mas não é de uma idéia que (1) afirma a existência e (2) nega a existência, mas sim de um animal. Segundo Quine pouco temos a ganhar em dizer que existe Pégaso no mundo da mitologia grega e não no mundo real, afinal, metáforas à parte, há só um mundo.

Não temos que concluir daí que tudo que existe ocupa espaço e tempo. Podemos admitir, por exemplo, a verdade do enunciado

(3) Há o número $9^{9^{9}}$

embora o número em questão seja objeto abstrato, não espacial e não temporal. O verbo 'há' em (3) é entendido no mesmo sentido de que em (1) e (2). A diferença entre os exemplos não está relacionada ao verbo 'há', mas sim nos substantivos 'Bucéfalo', 'Pégaso' e ' $9^{9^{9}}$ '.

A última parte do livro é intitulada Classe, Relação e Número e apresenta como primeiro item Atributos e Classes, onde o autor afirma que a matemática depende de objetos abstratos como números, funções, relações, classes e atributos. Segundo Quine, “os objetos abstratos de cujo

\footnotetext{
${ }^{1}$ Cavalo alado que figura na mitologia grega, presente no mito de Perseu e Medusa.

${ }^{2}$ Cavalo de guerra de Alexandre, o Grande, Rei da Macedônia.
} 
reconhecimento a matemática depende são, de fato, redutíveis, a uma porção que inclui somente as classes, ou atributos" (QUINE, 1944, p.179)

A questão abordada neste item é como diferem as classes dos atributos? Uma resposta é: atributos podem diferir entre si ainda que por acaso sejam atributos das mesmas coisas, enquanto que classes são sempre idênticas quando têm os mesmos membros.

Para especificar uma classe, temos que apresentar uma matriz que é satisfeita pelos membros da classe e só por eles, mas devemos enfatizar a semelhança entre classes e atributos, pois a determinação de um atributo depende da apresentação de uma matriz satisfeita pelos objetos que possuem o atributo e só por eles. A matriz não é o atributo. Assim a única diferença entre classes e atributos se encontra na condição de identidade, e neste caso as classes são muito mais claras que os atributos. Duas matrizes determinam a mesma classe quando satisfeitas pelos mesmos objetos.

O próximo item é Pertinência e identidade, e o autor começa diretamente com a noção de classe. Dizemos que um objeto x é membro de uma classe $\mathrm{y}$, ou que x pertence a y utilizando a notação ' $\mathrm{x} \varepsilon$ y', onde ' $\varepsilon$ ' é a inicial do verbo grego ' $\varepsilon$ ' $\tau i$ '. Na seqüência são formulados e apresentados os princípios fundamentais que regem este novo conectivo lógico, o conectivo de pertinência. Em seguida trata da questão da existência de classes e de uma álgebra de classes.

O tópico intitulado Relações aborda esta noção que se apresenta tão necessária à matemática quanto a de classe. As funções tão utilizadas em matemática são simplesmente relações. $\mathrm{O}$ autor afirma que classes de pares ordenados bastam para todos os propósitos das relações e adota a notação 'x;y' para designar o par ordenado que consiste de x e y na ordem indicada, assim, por exemplo, podemos considerar a função "metade de" como a classe dos pares ordenados 1/4;1/2, $1 / 3 ; 2 / 3,1 / 2 ; 1,4 ; 8$, etc.

Os pares devem ser concebidos como ordenados, de modo que os pares $\mathrm{x} ; \mathrm{y}$ e $\mathrm{y} ; \mathrm{x}$ sejam distintos para todos elementos x e y, pois queremos que o par 4;8 pertença à relação "metade de" e que Isaac;Abraão pertença a relação "filho de", mas não queremos que os pares opostos 6;3 e Abraão;Isaac pertençam à essas relações. Segundo o autor o princípio fundamental dos pares ordenados deve ser o seguinte:

(4) (x) (y) (z) (w) $\sim(\mathrm{x} \varepsilon \mathrm{V}-\mathrm{y} \varepsilon \mathrm{V}-\mathrm{z} \varepsilon \mathrm{V}-\mathrm{w} \varepsilon \mathrm{V}-\mathrm{x} ; \mathrm{y}=\mathrm{z} ; \mathrm{w}-\sim(\mathrm{x}=\mathrm{z}-\mathrm{y}=\mathrm{w}))$

Qualquer definição de par ordenado que satisfaça (4) seria adequada, mas é possível construir tal definição a base de teoria de classes. O par ordenado de quaisquer elementos x e y é a classe cujos membros são a classe unitária de x e a classe cujos membros são x e y. Esta formulação embora artificial satisfaz (4).

Dizer que $\mathrm{R}$ relaciona $\mathrm{x}$ a y é dizer que $\mathrm{x}$ e y são elementos tais que $\mathrm{x} ; \mathrm{y} \varepsilon \mathrm{R}$. Portanto, escrevendo ' $\mathrm{R}(\mathrm{x}, \mathrm{y})$ ' no sentido 'R relaciona $\mathrm{x}$ a y', adotamos a seguinte definição 
(5) 'R(x,y)' por ' $\mathrm{x} ; \mathrm{y} \varepsilon \mathrm{R}-\mathrm{x} \varepsilon \mathrm{V}-\mathrm{y} \varepsilon \mathrm{V}$ '

São apresentadas as noções de relação conversa que consiste dos pares inversos aos pares que pertencem a x, por exemplo, a conversa da relação "metade de" é a relação "duplo de", projeção, denotada por x'y, é a classe dos objetos que são relacionados por x a membros de y, por exemplo, se x é a relação "quadrado de" e y é a classe de números primos, temos que x"y é a classe de quadrados de números primos e produto relativo de $\mathrm{x}$ e $\mathrm{y}$, denotado por $\mathrm{x} \mid \mathrm{y}$, é a relação de qualquer objeto $\mathrm{z}$ a qualquer objeto $\mathrm{w}$ tal que $\mathrm{z}$ é relacionado por $\mathrm{x}$ a algum objeto que é relacionado por $\mathrm{y}$ a $\mathrm{w}$. Para exemplificar, se x é a relação de irmão e y é a relação de mãe , x|y é a relação de tio materno.

Na seqüência são definidas as espécies de relações, que podem ser simétricas, assimétricas, transitivas, intransitivas, antissimétricas e reflexivas. Uma relação R é simétrica se, sempre quando $\mathrm{R}(\mathrm{x}, \mathrm{y})$, segue-se que $\mathrm{R}(\mathrm{y}, \mathrm{x})$; e assimétrica se, sempre quando $\mathrm{R}(\mathrm{x}, \mathrm{y})$, segue-se que $\sim \mathrm{R}(\mathrm{x}, \mathrm{y})$. Para exemplificar temos que a relação de colega é simétrica e a relação de pai é assimétrica.

Uma relação $\mathrm{R}$ é chamada transitiva se, sempre quando $\mathrm{R}(\mathrm{x}, \mathrm{y})$ e $\mathrm{R}(\mathrm{y}, \mathrm{z})$, segue-se que $\mathrm{R}(\mathrm{x}, \mathrm{z})$; e intransitiva se, sempre quando $\mathrm{R}(\mathrm{x}, \mathrm{y})$ e $\mathrm{R}(\mathrm{y}, \mathrm{z})$, segue-se que $\sim \mathrm{R}(\mathrm{x}, \mathrm{z})$. Como exemplos temos a relação de inclusão é transitiva e a relação de pai é intransitiva.

Uma relação $\mathrm{R}$ é antissimétrica se, sempre quando $\mathrm{R}(\mathrm{x}, \mathrm{y})$ e $\mathrm{R}(\mathrm{y}, \mathrm{x})$, segue-se que $\mathrm{x}=\mathrm{y}$. Uma relação é reflexiva se, sempre quando x pertence ao domínio de $\mathrm{R}$, segue-se que $\mathrm{R}(\mathrm{x}, \mathrm{x})$.

$\mathrm{O}$ autor apresenta também a chamada relação unívoca se sempre que $\mathrm{R}(\mathrm{x}, \mathrm{y})$ e $\mathrm{R}(\mathrm{z}, \mathrm{y})$ então $\mathrm{x}$ = z. Podemos exemplificar, considere a relação "mãe de" que é unívoca, ao passo que a relação "filho de" não é unívoca.

Uma relação R é chamada transformação se ela e sua conversa são unívocas e tem o mesmo domínio. A relação "dobro de" é uma transformação, pois é unívoca e sua conversa "metade de" também é unívoca e ambas têm o mesmo domínio.

A teoria de classes e relações desenvolvidas ao longo desta parte do livro dependeu da aceitação de uma ontologia que admite objetos abstratos e classes como reais.

No tópico seguinte, intitulado Teoria virtual de classes e relações, o autor apresenta um modo alternativo de desenvolvimento para uma parte importante da chamada teoria de classes (e das relações) de modo "a formar parte da própria teoria da quantificação ou da identidade, evitando-se completamente quaisquer suposições ontológicas" (QUINE, 1944, p.218).

O método utilizado por Quine permite desenvolver uma teoria virtual de classes e relações que não depende de uma idéia de classe nem de pertinência e não implica questões ontológicas. Tal método permite "conservar todas as vantagens práticas da álgebra de classes e de alguns outros ramos das teorias das classes e relações, sem abandonar a lógica no sentido mais estrito: a teoria da quantificação" (QUINE, 1944, p. 221). 
O próximo item intitulado Números naturais apresenta a definição do conjunto dos números naturais. $\mathrm{O}$ autor utiliza a notação 'x para a classe unitária de $\mathrm{x}$, isto é a classe cujo único elemento é x. O número 0 , admitido como a classe dos primeiros 0 números, deve ser a classe vazia. $\mathrm{O}$ número 1, como classe do primeiro número será a classe '0; o número 2, como a classe dos primeiros dois números, será a classe ${ }^{1} 0 \mathrm{u}^{1} 1$ cujos membros são 0 e 1 ; o número 3 será ${ }^{1} 0 \mathrm{u}^{1} 1 \mathrm{u}^{\mathrm{C}} 2 \mathrm{e}$ assim por diante. De maneira mais concisa, podemos utilizar 2 é 1 u '1, 3 é 2 u '2 e, em geral, o número que sucede a $\mathrm{n}$ é n u 'n. Desta forma cada número natural possui sua definição. O passo seguinte é construir uma definição geral de número natural, segundo Quine, definir a classe Nn cujos membros são 0, 1, 2, etc. A definição 'Nn' como sendo ' 0 u '1 u '2 u etc.' não serve pois determina 'Nn' como abreviação de uma expressão que contém a palavra 'etc' que não foi definida. A solução devida a Frege depende de considerarmos que $\mathrm{Nn}$ possui 0 como membro e possui também o sucessor z u ' $\mathrm{z}$ de cada membro z. Segundo Quine

Essa condição sobre $\mathrm{Nn}$ ainda não determina completamente $\mathrm{Nn}$, pois a mesma condição é satisfeita também por toda classe a qual pertencem, além dos números naturais, quaisquer objetos adicionais. Porém, Nn é a classe mais estreita que satizfaz à dada condição. (QUINE, 1944, p. 225)

É a mais estreita das classes y tais que

$$
0 \varepsilon \mathrm{y}-(\mathrm{z}) \sim\left(\mathrm{z} \varepsilon \mathrm{y}-\sim \mathrm{zu}^{\mathrm{l}} \mathrm{z} \varepsilon \mathrm{y}\right)
$$

É a parte comum de todas as classes que satisfazem (6). Assim, o autor define Nn como a classe dos elementos $\mathrm{x}$ que pertencem simultaneamente a todas as classes y que satisfazem (6). $\mathrm{Na}$ seqüência são apresentadas as definições de adição, multiplicação e potenciação aritmética que dependem da noção de potência relativa de uma relação w, no sentido seguinte:

$\mathrm{w}^{0}=1, \mathrm{w}^{1}=\mathrm{w}, \mathrm{w}^{2}=\mathrm{w}\left|\mathrm{w}, \mathrm{w}^{3}=\mathrm{w}\right| \mathrm{w} \mid \mathrm{w}$, etc.

Como exemplo, o autor apresenta w como sendo a relação de pai, $\mathrm{w}^{2}$ é a relação de avô e $\mathrm{w}^{3}$ é a relação de bisavô. A soma $\mathrm{x}+\mathrm{y}$ é o sucessor do sucessor do sucessor... (y vezes) de x; isto é, onde w é a relação de sucessor, $\mathrm{x}+\mathrm{y}$ é o objeto que é relacionado a $\mathrm{x}$ por $\mathrm{w}^{\mathrm{y}}$.

A noção de produto admite uma definição análoga, pois x.y é o resultado de adicionar x, y vezes, a 0 . Finalmente, a potência aritmética $\mathrm{x} \wedge \mathrm{y}$ (onde o autor usa essa notação para evitar confusão com a potência relativa $\mathrm{x}^{\mathrm{y}}$ ) é o resultado de multiplicar 1 , y vezes, por x. O autor, ainda que rapidamente, fala sobre o princípio da indução matemática.

A construção posterior mais importante é a que introduz os números reais e o autor utiliza a definição devida a Whitehead e Russell, que interpreta os números reais como certas relações entre 
números naturais. Para exemplificar, o número real $\sqrt{2}$ identifica-se com a relação $\hat{y} \hat{z}\left(y \varepsilon N N_{-} z \varepsilon N N_{-} \mathrm{y} \cdot \mathrm{y}<2 . z \cdot z\right)$.

Segundo Quine, poderíamos “continuar as construções para incluir os números negativos e os números imaginários, como também os números infinitos cardinais e ordinais e as noções de diferencial e de integral, centrais a análise" (QUINE, 1944, p. 230). Para maiores detalhes sugere que se consulte sua obra Mathematical Logic, publicada em 1940.

O autor finaliza o livro apresentando algumas considerações sobre o resultado demonstrado por Gödel em 1931, sobre incompletude.

para que uma sistematização de lógica ou de matemática possa ser usada na demonstração de teoremas, não é preciso que forneça um método mecânico para a descoberta de demonstrações [...], mas é preciso que todo teorema possua uma demonstração (embora ainda não descoberta) haja um e que método mecânico pelo qual toda demonstração, uma vez encontrada, possa ser autenticada (QUINE, 1944, p. 231)

Se compararmos os tópicos abordados por Quine em seu livro "O Sentido da Nova Lógica" com o livro "Introduction to Logic and the methodology of deductive sciences" de autoria de Alfred Tarski, encontramos grande parte dos assuntos nas duas obras. A primeira parte do livro de Quine intitulada Teoria da Composição trata basicamente dos tópicos abordados por Tarski nos dois primeiros capítulos de seu livro, o capítulo I - Sobre o uso de variáveis e o capítulo II - Sobre o Cálculo Proposicional. A segunda parte do livro de Quine, cujo título é Teoria da Quantificação apresenta alguns tópicos abordados por Tarski no capítulo II - sobre o Cálculo Proposicional e no capítulo VI - Sobre o método dedutivo. É importante observar que os autores apresentam algumas diferenças relacionadas à notação utilizada. A terceira parte do livro de Quine intitulada Identidade e Existência tem uma interface com o capítulo III - Sobre a teoria da identidade, do livro de Tarski, sendo que Quine aprofunda um pouco mais o assunto, abordando aspectos ontológicos. A última parte do livro de Quine, chamada Classe, Relação e Número apresenta tópicos tratados por Tarski nos capítulos IV - Sobre a Teoria das Classes e V - Sobre a Teoria das Relações. Como podemos ver, os dois livros apresentam muitos tópicos em comum, e o fato de Tarski ser um dos mais renomados lógicos de todos os tempos, contribui para atestar a relevância e a importância da obra de Quine originalmente escrita em português.

\section{CONSIDERAÇÕES FINAIS}

Segundo (CRIPPA, 1978, p. 146), o livro O Sentido da Nova Lógica de Quine, embora ainda hoje conserve seu valor, aparentemente exerceu pouca influência nos estudos de lógica no Brasil. 
Acreditamos, no entanto, que as três obras tratadas neste artigo contribuíram para o interesse dos estudos de lógica no Brasil, e conversando com o Prof. Newton da Costa a esse respeito o mesmo disse que o livro de Amoroso Costa o influenciou e que o livro do Quine foi o primeiro livro de lógica moderna que leu. Segundo o Prof. Newton

O livro de Quine "O Sentido da Nova Lógica" foi o primeiro livro de lógica moderno que eu li. Na época era o único acessível. Quanto ao livro de Vicente F. da Silva, eu somente o li muito tempo depois de já possuir uma boa formação em lógica; quando eu comecei, a obra estava esgotada ou não era vendida nas livrarias comuns (penso que a primeira edição do livro era particular, editada pelo próprio Vicente). (COSTA, 2007)

A relevância da resposta do Prof. Newton da Costa reside no fato do mesmo ser o responsável pelo desenvolvimento de uma forte escola de lógica, inicialmente em São Paulo e Campinas, mas atualmente se estendendo por todo o país.

A semente estava plantada, mas só começaria a apresentar seus frutos no final da década de 50.

\section{REFERÊNCIAS}

AMOROSO COSTA, M. As ideas fundamentaes da mathematica. Rio de Janeiro: Papelaria e Litho-Typographia Pimenta de Meilo, 1929.

AMOROSO COSTA, M. As idéias fundamentais da matemática e outros ensaios. São Paulo: Convívio, 1981.

CARVALHO, J. M. Vicente Ferreira da Silva e o sentido da arte. Existência e Arte - Revista Eletrônica do Grupo PET - Ciências Humanas, Estética e Artes, São João Del-Rei, ano 1, n. 1, p. 1-10, jan./dez. 2005.. Disponível em: <http://www.ufsj.edu.br/Pagina/existenciaearte/Arquivos/VICENTE\%20FERREIRA\%20DA\%20SIL VA\%20E\%20O\%20SENTIDO\%20DA\%20ARTE.pdf>. Acesso em: 02 fev. 2007.

COSTA, N. C. A. Vicente Ferreira da Silva e a lógica. Revista Brasileira de Filosofia, São Paulo, v. 14, n. 56, p. 499-508, out.-dez. 1964.

COSTA, N. C. A. A obra de Vicente Ferreira da Silva em lógica. Revista Brasileira de Filosofia, São Paulo, v. 41, n. 174, p. 165-169, abr.-jun. 1994.

COSTA, N. C. A. Notícias [mensagem pessoal]. Mensagem recebida por <crmoraes@claretianas.com.br>em 29 abr. 2007.

CRIPPA, A. et al. As idéias filosóficas no Brasil - século XX - parte II. São Paulo: Convívio, 1978. 
MARITAIN, J.Elementos de filosofia II - a ordem dos conceitos - lógica menor. Trad. Ilza das Neves. 7 ed. Rio de Janeiro: Agir, 1972. 317 p.

MORAES, C. R. Uma História da Lógica no Brasil. 2007. 136 f. Tese (Doutorado em Ensino e Aprendizagem da Matemática e seus Fundamentos Filosófico-Científicos) - Instituto de Geociências e Ciências Exatas, Universidade Estadual Paulista, Rio Claro, 2007.

1. QUINE, D. B. Willard Van Orman Quine 1908-2000 Philosopher and Mathematician. Disponivel em <http://www.wvquine.org> . Acesso em: 03 jan. 2007.

QUINE, W. O. O sentido da Nova Lógica. São Paulo: Martins, 1944. 252 p.

SILVA, C. M. S. No paraíso dos símbolos: o surgimento da lógica e teoria dos conjuntos no Brasil. Disponível em: <http://www.ufes.br/circe/administrador/artigos/arquivos/artigo60.htm>. Acesso em: 24 set. 2004.

SILVA, V. F. Elementos de lógica matemática. São Paulo: Editora Cruzeiro do Sul, 1940.

TARSKi, A. Introduction to logic and to the methodology of deductive sciences. Translated by Olaf Helmer. New York: Dover Publications, 1995. 239 p. 